\title{
ADSORÇÃO DO AZUL DE METILENO POR REJEITO DE CAULIM QUIMICAMENTE TRATADO VISANDO SEU USO NA REMOÇÃO DE CORANTE EM SOLUÇÃO AQUOSA*
}

\author{
Cintia da Silva Matos ${ }^{1}$ \\ Verônica Scarpini Cândido ${ }^{2}$ \\ Edmarino Araujo Hildebrando ${ }^{3}$
}

\section{Resumo}

Foi notado que o rejeito originado a partir do beneficiamento do caulim é rico em silico-aluminatos, apresentando assim potencial em processo de adsorção. $O$ presente trabalho consiste em avaliar o potencial adsortivo do rejeito do caulim quimicamente tratado. Foi utilizado o corante de azul de metileno (AM) em solução aquosa para se ter o conhecimento de adsorção do rejeito de caulim in natura e calcinado a $700^{\circ} \mathrm{C}$ onde ambos foram submetidos a uma ativação química com $\mathrm{H}_{2} \mathrm{SO}_{4}$. Após o equilíbrio da amostra do rejeito do caulim junto ao azul de metileno, suas concentrações foram determinadas por espectrofotometria. Os resultados preliminares comprovam que o rejeito apresenta uma boa capacidade adsortiva para concentração de até $50,00 \mathrm{mg} / \mathrm{L}$ de AM, demostrando, potencial para ser utilizado na remoção de corantes em tratamento de afluentes.

Palavras-chave: Materiais adsorventes; rejeito de mineração; caulim.

\section{ADSORCING OF THE METHYLENE BLUE BY REJECTING CAULIMUM CHEMICALLY TREATED BY LOOKING FOR ITS USE IN THE REMOVAL OF AQUOSA SOLUTION}

\begin{abstract}
It was noticed that the tailings originated from the kaolin processing is rich in silicoaluminates, thus presenting potential in the adsorption process. The present work consists in evaluating the adsorptive potential of the kaolin reject chemically treated. The methylene blue dye (AM) in aqueous solution was used to obtain the adsorption knowledge of the kaolinite in natura and calcined at $700^{\circ} \mathrm{C}$ where both were submitted to chemical activation with $\mathrm{H}_{2} \mathrm{SO}_{4}$. After the kaolin tail sample was equilibrated to the methylene blue, its concentrations were determined by spectrophotometry. Preliminary results show that the waste presents a good adsorptive capacity for the concentration of up to $50.00 \mathrm{mg} / \mathrm{L}$ of $\mathrm{AM}$, showing the potential to be used in the removal of dyes in treatment of tributaries.
\end{abstract}

Keywords: Adsorbent materials; mining tailings; kaolin.

1 Graduanda em Engenharia de Materiais, Universidade Federal do Pará (UFPA), Faculdade de Engenharia de Materiais, Ananindeua, PA, Brasil.

2 Doutora em Ciência dos Materiais, Professora de graduação, Universidade Federal do Pará (UFPA), Faculdade de Engenharia de Materiais, Ananindeua, PA, Brasil.

3 Doutor em Engenharia Metalúrgica e de Materiais, Professor de graduação, Universidade Federal do Pará (UFPA), Faculdade de Engenharia de Materiais, Ananindeua, PA, Brasil. 


\section{INTRODUÇÃO}

Diversos estudos mostram que determinados argilominerais podem atuar com grande capacidade adsortiva em inúmeros processos industriais apresentando opções de baixo custo, baixa toxidade e fácil obtenção da superfície adsorvente para aplicação em área com graves problemas de contaminação [1].

Pesquisas indicam que a intercalação de moléculas orgânicas e inorgânicas nos espaçamentos interlamelares da caulinita é um método alternativo para a síntese de adsorventes que podem ser utilizados no tratamento de afluentes contendo poluentes, pois os argilominerais possuem uma forte capacidade de adsorção devido sua capacidade de troca catiônica e aniônica [2].

As argilas possuem a capacidade de sorver determinados cátions e ânions, além de poder trocar esses íons. Tais propriedades geralmente ocorrem em soluções aquosas. A capacidade de troca catiônica é uma propriedade importante das argilas, porque os íons permutáveis influem de forma significativa nas propriedades macroscópicas das argilas. Quanto menor for a partícula de argila, maior será a capacidade de troca iônica, talvez devido à maior área superficial disponível por unidade de volume [3].

Uma utilização da argila como adsorvente é na retenção de metais pesados, sendo um processo envolvendo diferentes mecanismos, e controlada por diferentes variáveis que podem interagir. Entre os trabalhos encontrados na literatura podem ser citados os que verificaram os efeitos de $\mathrm{pH}$, temperatura, concentração de sorbato e força iônica do meio para a retenção de níquel em ilita [4].

\section{MATERIAIS E MÉTODOS}

Utilizou-se como matéria-prima principal neste trabalho o rejeito de caulim. $O$ material de partida, foi caracterizado através de análise química (AQ) e difração de raios $X(D R X)$. A composição química do material de partida foi determinando através da técnica de fluorescência de raios $X(F R X)$. Para verificar as fases mineralógicas do rejeito efetuou-se análises de DRX utilizando-se um difratômetro modelo X'Pert Pro MPD (PANNalytical).

O mesmo foi peneirado a 200 mesh para se submetido ao um processo de ativação térmica na temperatura de $700{ }^{\circ} \mathrm{C}$ por um tempo de 2,0 horas utilizando um forno tipo mufla, em seguida a amostra é submetida a uma ativação química. A ativação é efetuada com ácido sulfúrico à $80^{\circ} \mathrm{C}$ por 3,0 horas em uma concentração de $4 \mathrm{M}$. Inicialmente a solução aquosa $4 \mathrm{M}$ de ácido sulfúrico, é adicionado sobre uma amostra de $4,5 \mathrm{~g}$ seca e desagregada, em seguida a mistura é levada a uma estufa por 3 horas, e a mistura obtida é filtrada e lavada com água destilada até que o ph do filtro fique em torno de 7,0. Com o material obtido é feito o experimento de adsorção a temperatura ambiente.

A partir de uma solução estoque de azul de metileno de concentração $1000 \mathrm{mg} / \mathrm{L}$ (1,0 g do corante dissolvidos em $1 \mathrm{~L}$ de água destilada), foram preparadas por diluição, soluções do corante de 10, 20, 50 e $100 \mathrm{mg} / \mathrm{L}$ feitas em balões volumétricos de $200 \mathrm{~mL}$. Foi então retirado cerca de $10 \mathrm{~mL}$ de cada solução e transferido para tubos de ensaios, logo após pesou-se uma alíquota de $100 \mathrm{mg}$ do rejeito de caulim "in natura" (amostra A) e rejeito calcinado (amostra B) e adicionou-se aos tubos de ensaio. As amostras foram agitadas inicialmente e permaneceram por 24 horas, sem agitação, a fim de confirmar o equilíbrio; após este período a eficiência de remoção do corante, foi observado visualmente e registrado através de imagens. 


\section{RESULTADOS E DISCUSSÃO}

$\mathrm{Na}$ Tabela 1, está o resultado da análise química por fluorescência de Raio-x da argila caulínitica. Observa-se que os óxidos principais que compõem o rejeito são o $\mathrm{SiO}_{2}$ e $\mathrm{A}_{2} \mathrm{O}_{3}$, que denota que o referido material é composto por minerais que apresentam em sua constituição principalmente o alumínio e o silício que são os principais constituintes das argilas cauliníticas.

Tabela 1. Composição química do rejeito de caulim "in natura" em percentagem de óxidos.

\begin{tabular}{cc}
\hline \% Óxidos & Rejeito de Caulim \\
\hline $\mathrm{SiO} 2$ & 46,51 \\
\hline $\mathrm{Al} 2 \mathrm{O} 3$ & 38,46 \\
\hline $\mathrm{Fe} 2 \mathrm{O} 3$ & 0,94 \\
\hline $\mathrm{TiO} 2$ & 1,01 \\
\hline $\mathrm{Na} 2 \mathrm{O}$ & --- \\
\hline $\mathrm{PF}$ & 13,05
\end{tabular}

Fonte: Relatório de caracterização mineral por DRX e FRX

A Figura 1 apresenta os resultados macroscópicos dos ensaios de adsorção em concentrações iniciais de $10,20,50,100 \mathrm{mg} / \mathrm{L}$ do corante para as amostras relacionadas ao rejeito "in natura" e o rejeito calcinado ativado quimicamente $\left(\mathrm{H}_{2} \mathrm{SO}_{4}\right)$.

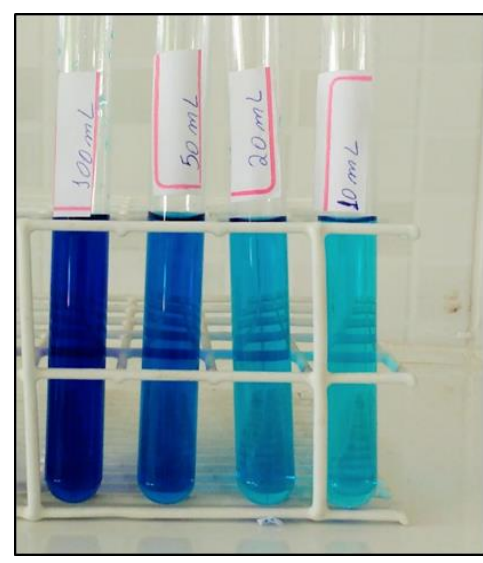

A)

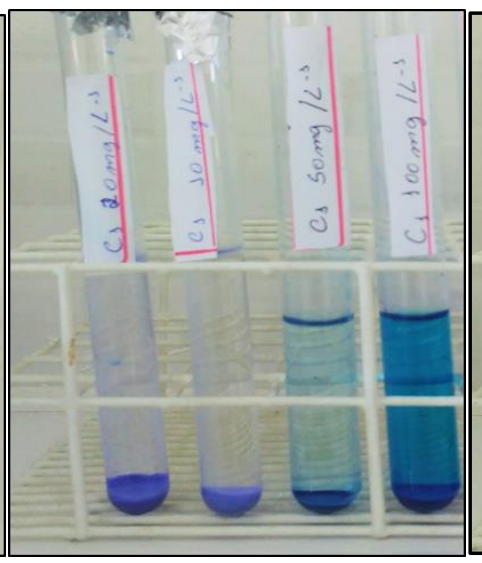

B)

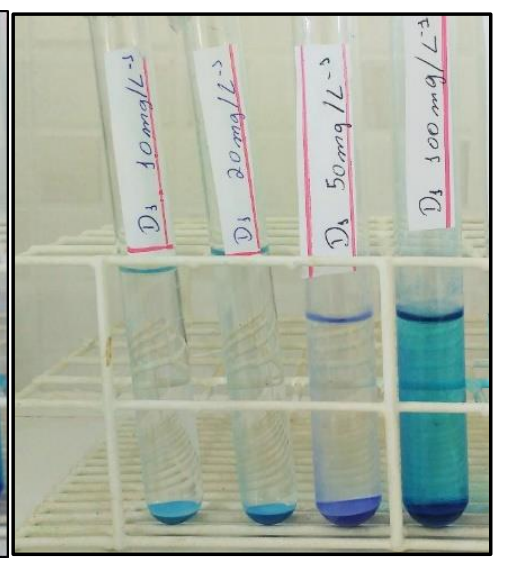

C)

Figura 1 - Resultados macroscópicos dos ensaios de adsorção: (A) concentração inicial do corante; (B) amostras do rejeito do caulim "in natura"; (C) amostras do rejeito calcinado ativado quimicamente.

Observa-se visualmente que ambas as amostras, rejeito "in natura" (Amostra C) e rejeito calcinado ativado quimicamente (Amostra D), apresentam as soluções sobrenadantes com desempenhos semelhantes quanto à variação da tonalidade de cor do azul de metileno (AM) principalmente na faixa de concentração de 10 a 25 $\mathrm{mg} / \mathrm{L}$; e conforme mostrado na Figura 2 acima, pode-se dizer que existe uma diminuição da eficiência na remoção do corante por parte da amostra C (Figura 2B) 
com o aumento na concentração da solução de azul de metileno principalmente para concentrações acima de $20 \mathrm{mg} / \mathrm{L}$ de AM. Já na amostra D (Figura 2C) pode-se observa um aumento da eficiência na remoção do corante (AM) nas concentrações acima de $50 \mathrm{mg} / \mathrm{L}$.

Com as soluções sobrenadantes obtidas após os ensaios de adsorção entre as amostras de rejeito de Caulim (Calcinado e "in natura") quimicamente tratado e solução de azul de metileno (AM) foi possível determinar através de ensaios de espectrofotometria UV-Visível a concentração de AM que não foi absorvido pelo rejeito nas concentrações de 10, 20, 50 e 100 mg.L-1 no material "in natura" e no calcinado ativado quimicamente por $\mathrm{H}_{2} \mathrm{SO}_{4}$.

Tabela 2 - Concentração e absorbância do material

\begin{tabular}{lllll}
\hline CONCONC. & CONCENTRAÇÃO & ABSORBÂNCIA & CONCENTRAÇÃO & ABSORBÂNCIA \\
A.M $\left(\mathrm{mg} \cdot \mathrm{L}^{-1}\right)$ & $\mathrm{C}\left(\mathrm{mg} \cdot \mathrm{L}^{-1}\right)$ & $\mathrm{C}$ & $\mathrm{D}\left(\mathrm{mg} \cdot \mathrm{L}^{-1}\right)$ & $\mathrm{D}$
\end{tabular}

\begin{tabular}{lllll}
\hline 10 & 0,408 & 0,018 & 0,045 & 0,002 \\
\hline 20 & 1,678 & 0,074 & 0,362 & 0,016 \\
\hline 50 & 1,994 & 0,088 & 1,880 & 0,083 \\
\hline 100 & 43,460 & 1,918 & 6,866 & 0,303 \\
\hline
\end{tabular}

É possível observar através da espectrofotometria que o material calcinado ativado quimicamente $\left(\mathrm{H}_{2} \mathrm{SO}_{4}\right.$ por 3 horas) apresenta uma boa capacidade adsortiva na concentração de 10, 20, e 50 mg.L-1. O material "in natura" ativado quimicamente $\left(\mathrm{H}_{2} \mathrm{SO}_{4}\right.$ por 3 horas) obteve melhores resultados na concentração de 10 e $20 \mathrm{mg} . \mathrm{L}-$ 1. Desta forma, o rejeito pode ser utilizado como um material adsorvente de baixo custo, já que este possui potencial para desempenhar adsorções até determinadas concentrações.

A Figura 2 mostra um gráfico linear no qual consta suas concentrações após a realização da espectrofotometria do material sobrenadante que continha o rejeito do Caulim "in natura" ativado quimicamente como adosrvente, a concentração de azul de metileno, 10, 20 e $50 \mathrm{mg} . \mathrm{L}-1$, teve grande capacidade adsortiva.

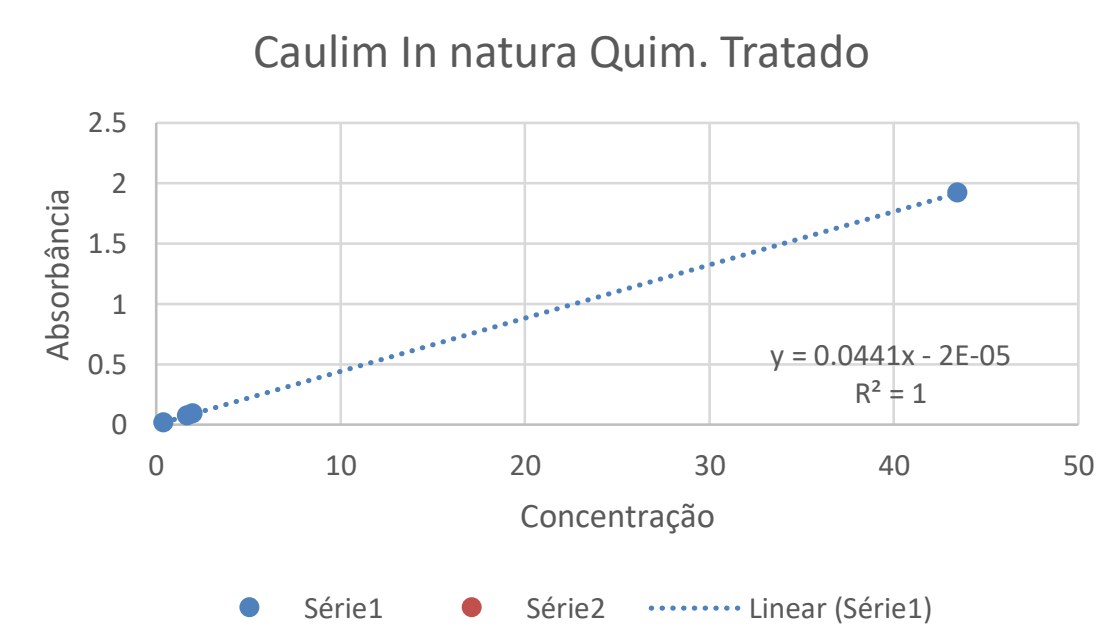

Figura 2. Espectrofotometria do material sobrenadante após o ensaio de adsorção com rejeito do Caulim "in natura".

Conforme análise da Figura 3, o rejeito do Caulim calcinado ativado quimicamente, teve o melhor desempenho obtendo uma concentração de azul de metileno na 
solução sobrenadante inferior dos demais materiais, desta forma, tendo uma maior capacidade adsortiva em todas as faixas de concentração.

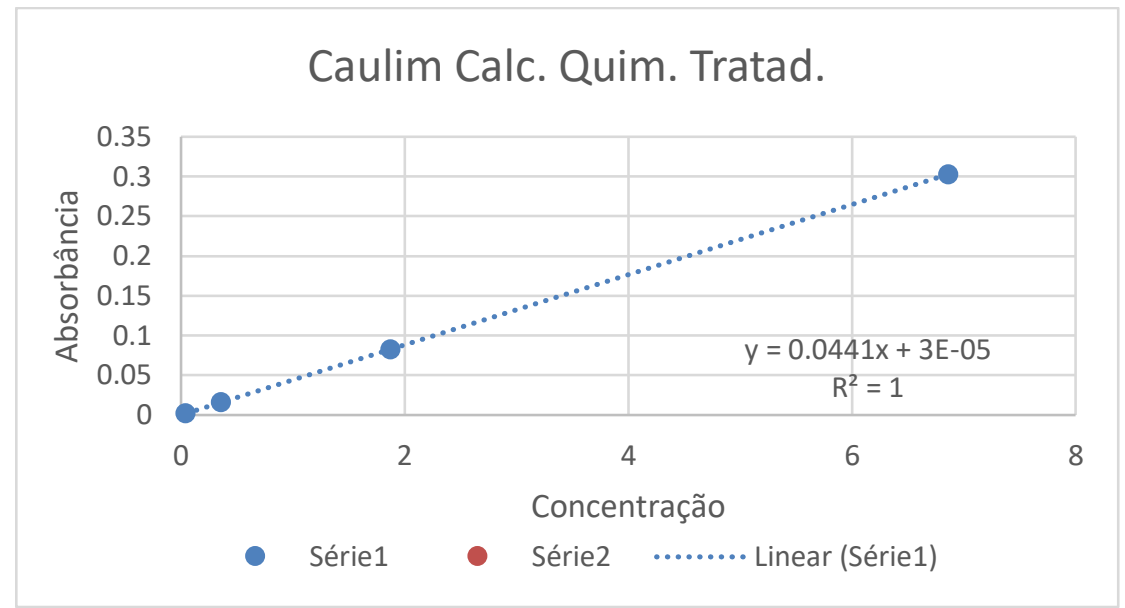

Figura 3.Espectrofotometria do material sobrenadante após o ensaio de adsorção com rejeito do Caulim Ativado termicamente.

\section{CONCLUSÃO}

As conclusões desta pesquisa, levam a acreditar que o rejeito do caulim quimicamente tratado mostra-se nas condições estudadas ser bastante promissor quanto a adsorção do azul de metileno apresentando uma boa eficiência na remoção do corante para concentração de até $50 \mathrm{mg} / \mathrm{L}$.

O material obtido demonstra ter potencial para aplicação tecnológica, principalmente se usada de forma alternativa como adsorvente de baixo custo, pois o mesmo será produzido a partir de um material que é descartado durante etapa de produção sendo assim considerado resíduo. Isso significa que o rejeito poderá sair da condição de poluente para a condição de solução de problemas ambientais.

\section{Agradecimentos}

Agradecemos à parceria do LEQ/UFPA e PIBIC/UFPA, e principalmente ao meu orientador pela paciência e por acreditar em meu potencial.

\section{REFERÊNCIAS}

1. CALDARONE, M.A.; GRUBER, K.A.; BURG, R.G. High-reactivity metakaolin: a new generation mineral admixture. Concrete International, v.16, n.11, p.37-40, 1994. 2. MONTE et al 2003, Gardolinski et al. 2003, Passos 2007

3. SOUZA, S. P. apud. LOPES, T. J. Desenvolvimento des estratégias para aperfeiçoar a utilização de argilas adsorventes em processos industriais. Tese (Doutorado em Engenharia Quimica) - Departamento de Engenharia Química e Engenharia de Alimentos, Universidade Federal de Santa Catarina, Florianópolis, 2006. 
4. ECHEVERRÍA, J.; INDURAIN, J.; CHURIO, E.; GARRIDO, J. Simultaneous effect of $\mathrm{pH}$, temperature, ionic strength, and initial concentration on the retention of $\mathrm{Ni}$ on illiteColloids and, Surfaces A: Physicochemical end Engineering Aspects, vol. 218, no 1-3, 29, p. 175-18, 2003. 